\title{
Effects of solid friction modifier on friction and rolling contact fatigue damage of wheel-rail surfaces
}

\author{
Jingdong SONG ${ }^{1,2}$, Lubing SHI ${ }^{1}$, Haohao DING ${ }^{1, *}$, Radovan GALAS ${ }^{3}$, Milan OMASTA ${ }^{3}$, Wenjian WANG ${ }^{1}$, Jun GUO $^{1}$, \\ Qiyue LIU ${ }^{1}$, Martin HARTL ${ }^{3}$ \\ ${ }^{1}$ Tribology Research Institute, State Key Laboratory of Traction Power, Southwest Jiaotong University, Chengdu 610031, China \\ ${ }^{2}$ School of Mechanical Engineering, Xi'an Jiaotong University, Xi'an 710049, China \\ ${ }^{3}$ Faculty of Mechanical Engineering, Brno University of Technology, Brno 616 69, Czech Republic
}

Received: 18 July 2020 / Revised: 14 December 2020 / Accepted: 19 April 2021

(C) The author(s) 2021.

\begin{abstract}
In railway network, friction is an important factor to consider in terms of the service behaviors of wheel-rail system. The objective of this study was to investigate the effect of a solid friction modifier (FM) in a railway environment. This was achieved by studying the friction, wear, and rolling contact fatigue (RCF) damage on the wheel-rail materials at different slip ratios. The results showed that when a solid FM was applied, the friction coefficient decreased. After the solid FM was separated from the wheel-rail interface, the friction coefficient gradually increased to its original level. With the application of the solid FM, the wear rates of the wheel-rail decreased. In addition, the thickness and hardness of the plastic deformation layers of the wheel-rail materials were reduced. The worn surfaces of the wheel-rail were dominated by pits and RCF cracks. Without the FM, RCF cracks ranged from 84 to $120 \mu \mathrm{m}$, and subsurface cracks were generated. However, with the FM, RCF cracks ranged from 17 to $97 \mu \mathrm{m}$ and no subsurface cracks were generated. These findings indicate possible methods of improving the performance of railway rolling stock by managing friction, and reducing wear and permanent RCF damage affecting both the wheels and rails.
\end{abstract}

Keywords: wheel-rail; solid friction modifier (FM); friction; wear; rolling contact fatigue (RCF) damage

\section{Introduction}

In railway network, an appropriate friction level can accelerate and decelerate a train. However, low friction can cause serious safety problems [1, 2]. Meanwhile, the initiation and propagation of rolling contact fatigue (RCF) cracks on railway wheels are serious problems in the field [3, 4]. Experiments and calculation models for degraded friction [5] and wear and RCF [6] have been studied recently. The friction level at the wheelrail interface played a significant role in traction and braking.

A friction coefficient of the wheel-rail interface that is too low (less than 0.1) causes poor friction for trains during braking, which can result in safety issues by increasing the braking distance [7]. However, a high friction coefficient under dry conditions (0.5-0.8) could have a negative effect on train operations when braking and accelerating, or cause surface damage (RCF or wear) [8]. Friction modifiers (FMs) can be applied to the top surface of the rail to achieve intermediate friction coefficient (0.3-0.4) in the third body layer. This reduces wear and surface damage by reducing the traction forces without compromising the braking or friction functions. Furthermore, a FM can be used in some critical sections (such as curves) to reduce the friction coefficient, however they would not be applied at inclines where higher friction levels would be needed for traction and braking. Friction control at the top of the rail has been used in

* Corresponding author: Haohao DING, E-mail: haohao.ding@swjtu.edu.cn 
railway maintenance using liquid or solid FMs at the wheel-rail interface to reduce the friction coefficient, thereby reducing the wheel-rail wear, damage, and noise [9-13].

FMs can be applied by trackside applicators or from train-mounted systems, which are popular because no access to the track is required and the amount of FM used can be easily controlled. Considering the classification, top-of-rail FMs are available in the form of solid sticks, liquids/solutions, foam, and gels [14]. In addition, FMs for applications are divided into passenger transit (conventional trains), high-speed railways, freight corridors, and mixed traffic. The solid form of FM, often referred to as high positive friction (HPF) [14, 15], is provided with the active components embedded in a thermoset polymeric matrix, and the HPF sticks are applied directly to the wheel tread. Then, under load via a constant force spring, the HPF stick material is transferred to the wheel, and the resin material oxidizes under high temperatures at the wheel-rail interface. This leaves a thin film of the dry solid FM, which plays a role in managing the friction coefficient at the wheel-rail interface.

Third bodies applied to the rail head or wheel tread surfaces, such as deliberately applied sand, can compromise the wheel-rail electrical contact and result in loss of train detection owing to the resistance of third body layers in wheel-rail contact (wheel-rail isolation) [16]. However, the HPF solid modifier does not cause wheel-rail isolation [14].

Water-based friction management has some disadvantages [17], including quicker vaporization in high-contact-temperature scenarios, such as high axle loads, hot weather, and tight curves. Furthermore, Eadie et al. [13] studied a water-based suspension called Keltrack and found that the FM application had a very small pass effect compared to dry conditions. There is an optimum amount of FM and increasing application beyond this amount has no extra benefits. FMs can be used to increase or decrease the friction level at wheel-rail interfaces. Many FMs have been used to increase the friction level at the wheel-rail interface [18, 19], and Lewis et al. [14] summarized that FMs could also been applied to decrease the high friction coefficient $(0.6-0.7)$ to an intermediate level
(0.3-0.4), in ways that will improve the braking or accelerating process.

$\mathrm{RCF}$ is one of the most common types of damage occurring on wheel-rail surfaces [20, 21]. RCF damage is influenced by many parameters, including wheel-rail materials, loading pressure, lubrication, and running conditions [8, 22]. Meanwhile, the wear and RCF mutually affect each other [23,24]. Through simulations and experiments, Donzella et al. [25] and Guo et al. [26] found that wear could eliminate RCF cracks on wheel-rail surfaces. A sensitivity analysis showed that the probability of fatigue failure was dependent on the fatigue strength and material defect distribution [27]. The application of a developed criterion for predicting the crack growth for different loading states showed good agreement with the experimental results [28]. It should be noted that the improper application of liquid media (such as liquid lubrication or liquid FM) to the wheel-rail surfaces might accelerate the development of RCF cracks and damage $[29,30]$ due to hydro-pressurization. Hardwick and Lewis [31] studied the effects of liquid FMs on pre-existing RCF damage cracks and found that a lower viscosity caused faster crack growth. Solid FMs are attracting increasing attention owing to their convenient installation and application. However, the effect of a solid FM on RCF damage has not yet been systematically explored.

In this study, a solid FM is developed. The wheel-rail rolling-sliding tests were conducted with and without solid FM on the MMS-2A rolling-sliding test machine. The effect of a solid FM on friction, wear, and damage was studied. Meanwhile, the RCF surface cracks and subsurface cracks were explored in detail using microscopic methods.

\section{Experimental}

All tests were performed under dry conditions using an MMS-2A rolling-sliding test machine (Jinian Yihua Tribology Testing Technology Co., Ltd., China), which was previously used in the wheel-rail contact studies $[18,32]$, as shown in Fig. 1 . The upper specimen (wheel roller, 7 in Fig. 1) and lower specimen (rail roller, 6 in Fig. 1) were powered and controlled by the directcurrent motor (DC motor, 1 in Fig. 1) through the transmission gears. Different rotational speeds of the 


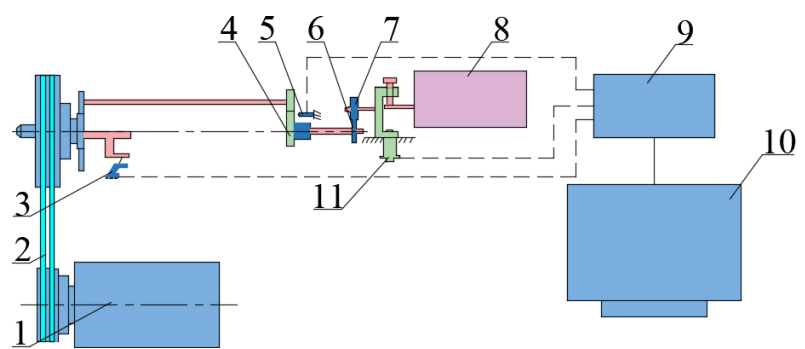

Fig. 1 MMS-2A rolling-sliding test machine. 1-DC motor; 2-belt; 3-torque sensor; 4-driving shaft gear; 5-revolution sensor; 6-lower specimen (rail roller); 7-upper specimen (wheel roller); 8-driven shaft gear; 9-controller; 10-computer; 11-normal force sensor.

upper and lower specimens were achieved by changing the gear pairs. There are six gear pairs to perform six different slip ratios, $0.17 \%, 0.91 \%, 2.38 \%, 3.83 \%$, $4.55 \%$, and $9.43 \%$, respectively. The upper roller is fixed in a swinging bracket, to which a normal force can be applied by a compressed spring. The tangential and normal forces at the wheel-rail interface were measured and recorded automatically on a computer using a torque sensor (3 in Fig. 1, TQ-660, Beijing Shitongkechuang Technology Co., Ltd., China, 0-15 N.m) and a load sensor (11 in Fig. 1, LC-7, Putianshi Hongfei Sensor Co., Ltd., China) (0-2 kN, measurement error $\pm 5 \%$ ). The test apparatus monitors the parameters of vertical load, friction moments, and friction coefficient in the entire process via a computer program (10 in Fig. 1) and records the parameter variation in real time.

The diameters of the wheel-rail rollers were $40 \mathrm{~mm}$, with a contact width of $5 \mathrm{~mm}$ (Fig. 2). Wheel-rail rollers were cut from the CL60 wheel tread and the U75V rail head, respectively. The chemical compositions of the wheel-rail materials are listed in Table 1. The solid FM investigated in this study was developed by us. The composition and production processes are as follows. The composition was polytetrafluoroethylene (PTFE, $40 \mathrm{wt} \%)+$ molybdenum (MoS2 100-300 mesh,

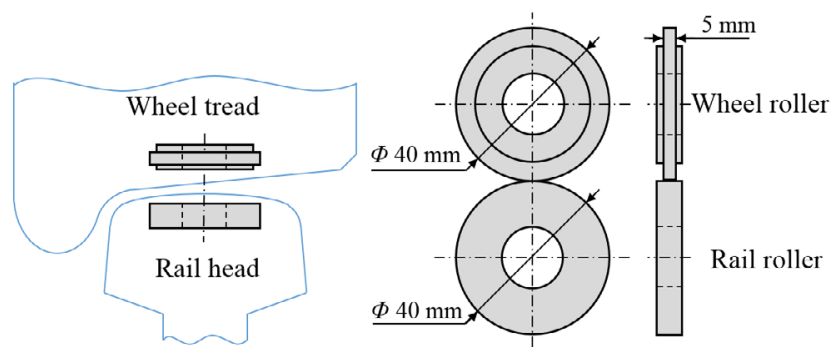

Fig. 2 Geometries and sampling positions of wheel-rail rollers.
Table 1 Chemical compositions of wheel-rail materials (wt\%).

\begin{tabular}{cccccc}
\hline Material & $\mathrm{C}$ & $\mathrm{Si}$ & $\mathrm{Mn}$ & $\mathrm{P}$ & $\mathrm{S}$ \\
\hline Wheel & $0.67-0.77$ & $0.15-1.00$ & $0.60-0.90$ & $\leq 0.03$ & $\begin{array}{c}0.005- \\
0.040\end{array}$ \\
Rail & $0.71-0.80$ & $0.50-0.80$ & $0.70-1.50$ & $\leq 0.03$ & $\leq 0.03$ \\
\hline
\end{tabular}

$30 \mathrm{wt} \%)+$ talcum (10 wt $\%, 100-300$ mesh $)+$ carbon fiber (20 $\mathrm{wt} \%)$. The production processes were as follows: PTFE, MoS2, talcum, and carbon fiber powders were mixed, dried for $10-15 \mathrm{~min}$ at $60-90{ }^{\circ} \mathrm{C}$, and then pressed into a solid cylinder (3-5 MPa, 20-30 min).

During the test, the rotational speed of the rail roller, $v_{\text {rail, was }} 200 \mathrm{rpm}$. The rotational speed of the wheel roller, $v_{\text {wheel, }}$ was lower than that of the rail roller. The slip ratios $\left(\left(v_{\text {rail }}-v_{\text {wheel }}\right) / v_{\text {rail }}\right)$ were $0.17 \%$, $0.91 \%, 2.38 \%, 3.83 \%, 4.55 \%$, and $9.43 \%$, respectively. A normal force of $1,100 \mathrm{~N}$ was loaded on the wheel roller, leading to a contact pressure of $900 \mathrm{MPa}$ between the wheel-rail rollers. The solid FM was pressed on the wheel surface with a dead weight (Fig. 3). The contact force between the solid FM and the wheel roller was $10 \mathrm{~N}$.

Two groups of tests were conducted. The first group, Group 1, was designed to study the effect of the solid FM on the friction coefficient. Tests were carried out under dry conditions without the FM for $3 \mathrm{~min}$, and then the solid FM was pressed on the wheel roller for a further $3 \mathrm{~min}$. The solid FM was then separated from the wheel surface and the tests were continued for approximately $15 \mathrm{~min}$. The second group, Group 2, was designed to explore the effect of the solid FM on the wear and damage of the whee-rail materials. Tests were conducted under dry conditions without the FM for $100 \mathrm{~min}$, and then the solid FM was pressed on the wheel surface and tests were continued for a further $200 \mathrm{~min}$. For the tests in Group 2, the slip ratio was $0.91 \%$.

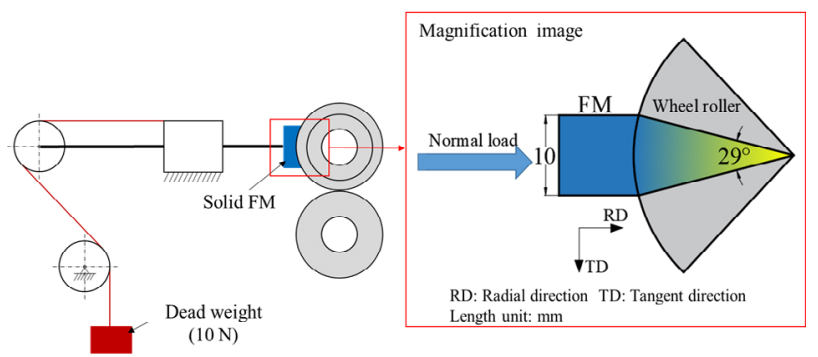

Fig. 3 Feeding method of solid FM on wheel-rail interface. 
The wheel-rail rollers were ultrasonically cleaned in ethanol, dried, and weighed using an electronic balance (TG328A, Shangtian Precision Instrument Co., Ltd., China, measurement accuracy: $0.0001 \mathrm{~g}$ ) before and after testing. The wear rate of the wheel-rail roller was defined as the ratio of weight loss to rolling distance $(\mu \mathrm{g} / \mathrm{m})$. The hardness of the wheel-rail rollers was measured using a Vickers hardness instrument (MVK-H21, Akashi, Japan). The worn surfaces and RCF cracks were inspected using an optical microscope (OM, BX60M, Olympus, Japan) and a scanning electron microscope (SEM, JSM-7001F, JEOL Ltd., Japan).

\section{Results}

\subsection{Friction coefficient}

Figure 4 shows the changes in the friction coefficient from the tests in Group 1. In the first 3 min of contact under dry conditions for the six different slip ratios, some tiny cracks were generated in the new wheel-rail rollers. This closely resembles the service state of the wheel-rail surfaces in the field. Conversely, if a solid FM is applied to a new wheel-rail interface, it is difficult to initiate surface damage. Hardwick et al. [31] has demonstrated the benefits of pre-existing RCF cracks for this solid FM friction management experimental study. The friction coefficients were relatively high. When the solid FM was applied after $3 \mathrm{~min}$, all the friction coefficients decreased. After the solid FM was separated after $6 \mathrm{~min}$, the friction coefficient increased gradually to its previous level.

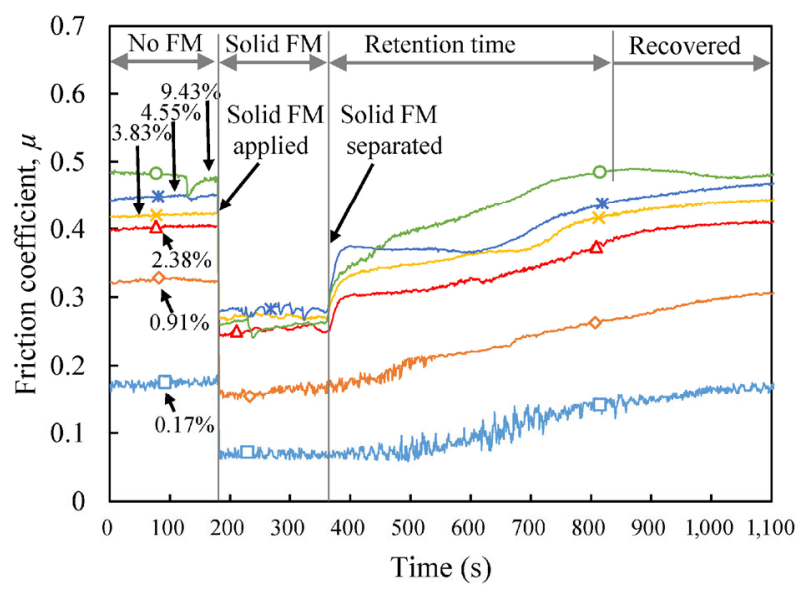

Fig. 4 Friction coefficient as a function of time.
Based on the friction coefficient curves (Fig. 4), the average friction coefficients under dry conditions without any FM (0-3 min) and with the solid FM applied (3-6 $\mathrm{min}$ ) could be obtained, as shown in Fig. 5 . It is clear that as the slip ratio increases, the friction coefficient increases sharply when the slip ratio is less than approximately $1 \%$, and then remains relatively stable when the slip ratio is greater than $1 \%$. When a solid FM was applied, the stable friction coefficient decreased from the range of $0.4-0.5$ to $0.2-0.3$.

As shown in Fig. 4, after the FM was separated from the wheel surface, the friction coefficient remained relatively low and then increased gradually, which means that the FM continued to work at least partially, for a period of time. The time before the friction coefficient recovered to the level before the application of the FM was defined as the retention time. Figure 6 shows the retention time for different slip ratios. It is clear that as the slip ratio increases, the retention time of the solid FM decreases.

\subsection{Wear of wheel-rail materials}

To explore the effect of the solid FM on the wear and damage of wheel-rail materials, tests were performed

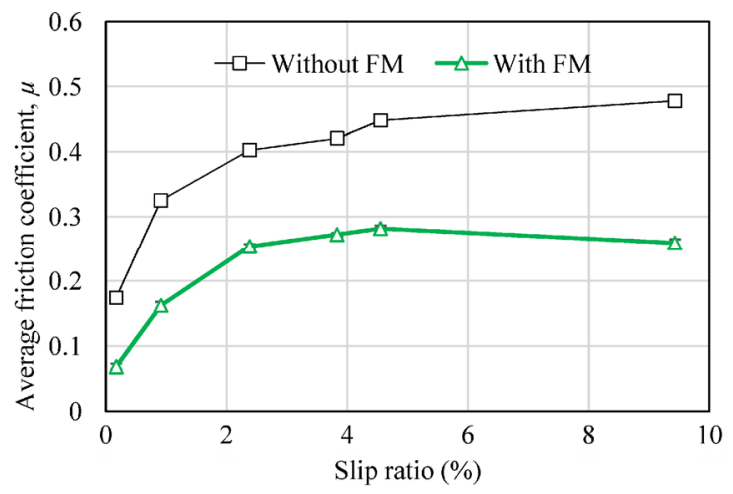

Fig. 5 Average friction coefficient as a function of slip ratio.

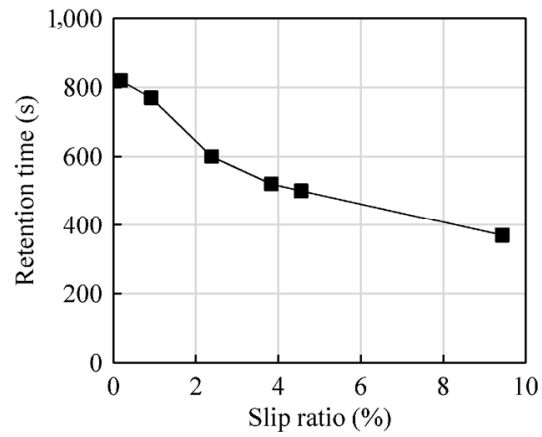

Fig. 6 Retention time as a function of slip ratio. 
without the FM for $100 \mathrm{~min}$, and then continued for 200 min with or without the FM at a slip ratio of $0.91 \%$. Figure 7 shows the wear rates of the wheel-rail rollers. The wear rate $\gamma$ in the test was defined by the following equation:

$$
\gamma=\frac{\gamma_{\mathrm{a}}-\gamma_{\mathrm{b}}}{L}
$$

where $\gamma_{\mathrm{a}}$ and $\gamma_{\mathrm{b}}$ are the sums of the weights of the wheel-rail rollers before and after the wear tests, respectively, and $L$ is the rolling contact distance between the wheel-rail rollers. With FM, the wear rates of wheel-rail were decreased to $50 \%$ and $65 \%$ of those without FM.

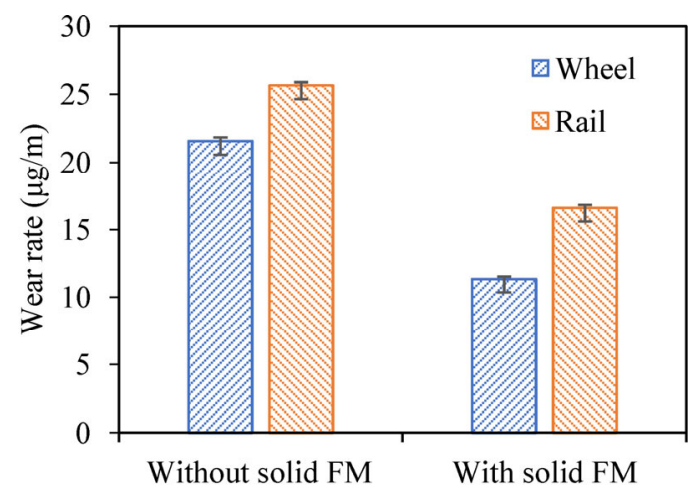

Fig. 7 Wear rates of wheel-rail.

\subsection{Surface and subsurface damages}

Under dry conditions without the FM, the worn wheel surface was relatively smooth with some pits. The surface damage of the rail was more severe than that of the wheel surface. Figure 8 shows OM images of the worn surfaces on the wheel-rail rollers under dry conditions with the FM. The OM observations indicate that the application of the solid FM had no apparent effect on the wheel damage, and only a few small pits were observed, however there was slight rail damage.
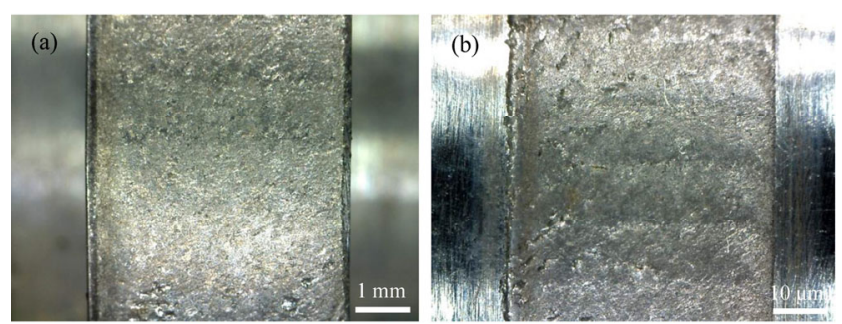

Fig. 8 OM images of worn surfaces with solid FM applied: (a) wheel and (b) rail.
Figure 9 shows the hardness of the cross sections of the wheel-rail rollers. With the solid FM, the surface hardness values of the wheel-rail rollers were clearly lower than those under the dry conditions without the FM. Meanwhile, the hardness gradually decreased with depth increasing. Furthermore, with the solid FM, the decrease in hardness was sharper. Thus, the hardening layers on the wheel-rail rollers with the application of solid FM were thinner than those without FM. Figure 10 shows the plastic deformation of the wheel-rail materials. With the solid FM, the thicknesses of the plastic deformation layers of the wheel-rail materials $(60-70 \mu \mathrm{m})$ were smaller than those under the dry conditions without the FM $(80-100 \mu \mathrm{m})$. The plastic deformation and hardening behaviors are closely related to the friction coefficient. Under cyclic rolling-sliding tests, the friction force led to the plastic flow of the wheel-rail materials. The microstructures

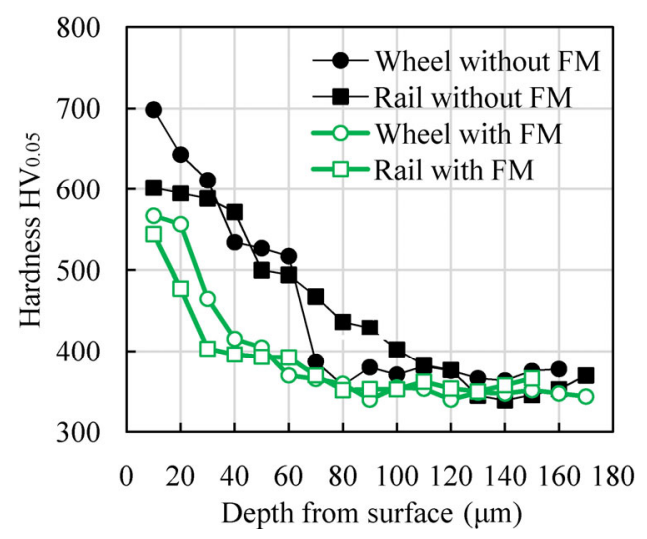

Fig. 9 Hardness of wheel-rail as a function of depth.
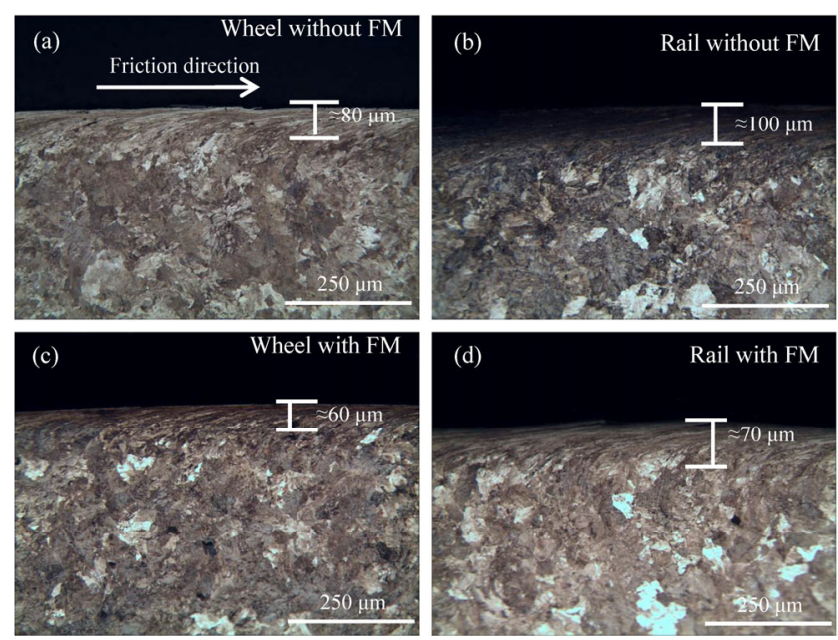

Fig. 10 Plastic deformation without FM applied: (a) wheel and (b) rail; with solid FM applied: (c) wheel and (d) rail. 
were deformed, broken, and refined under cyclic loads, resulting in work hardening. With the application of the FM, the friction coefficient was lower; thus, the plastic deformation layer and hardness value were also lower.

Figure 11 shows the OM images of the RCF cracks on the cross sections of the wheel-rail roller. With the solid FM, Figs. 11(a) and 11(b) show that fewer cracks were generated than those without FM. Meanwhile, as shown in Fig. 11(b), more cracks were generated on the rail roller than on the wheel roller. The length, depth, and angle of the RCF cracks were measured, as shown in Fig. 12. The depth of the cracks decreased on the wheel rollers, but there was almost no change on the rail rollers. Under cyclic normal and friction forces, plastic deformation accumulates. When the surface shear stress exceeded the strain limit of the wheel-rail materials, cracks were initiated and developed further.
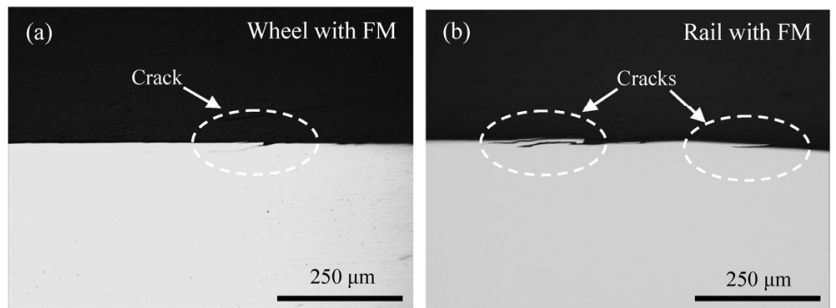

Fig. 11 OM images of RCF cracks on cross sections with solid FM applied: (a) wheel and (b) rail.
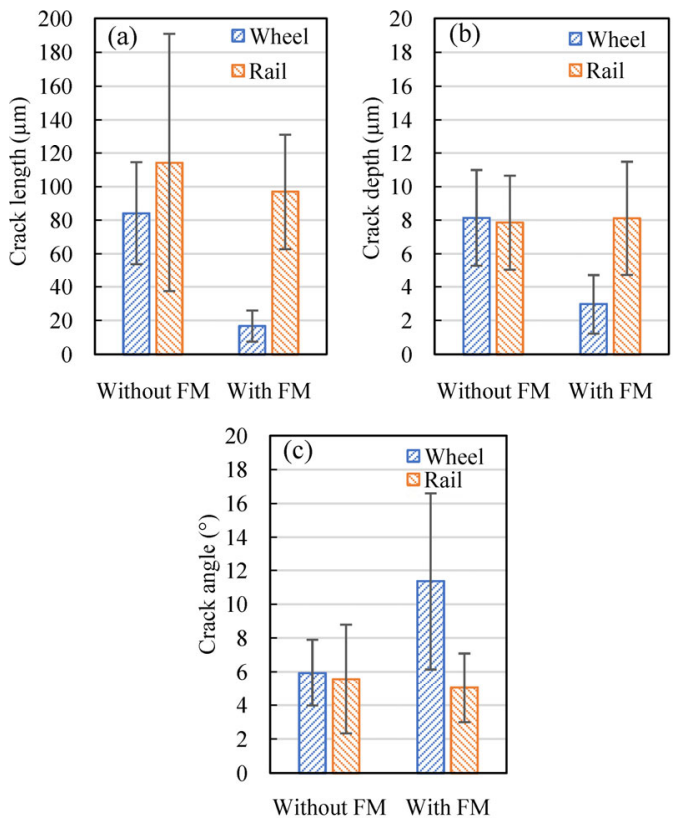

Fig. 12 RCF cracks: (a) length, (b) depth, and (c) angle.
In the current study, under dry conditions without the FM, the cracks tended to propagate along the plastic deformation line. Subsurface cracks were also generated. Figure 13 shows SEM images of RCF cracks on the wheel-rail roller with the FM application. It can be seen that the RCF crack fractured under cyclic loads, leading to wear loss of the material. With the solid FM applied as shown in Figs. 13(a) and 13(b), the RCF damage was milder and no subsurface cracks were observed. Owing to the friction force, the maximum stress occurred at the subsurface. Without the FM, the friction force was high, which promoted the generation of subsurface cracks. With the FM, the friction force was low; thus, cracks tended to initiate at the surface.
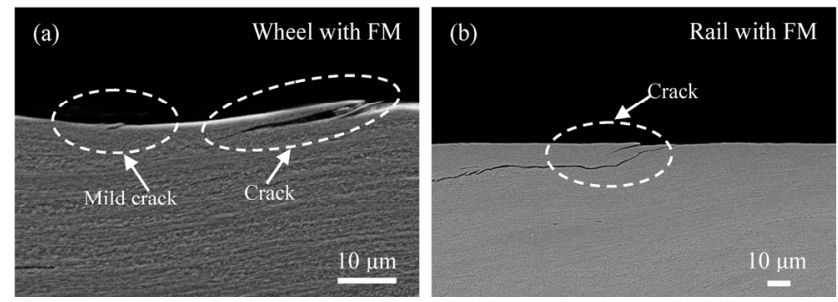

Fig. 13 SEM images of RCF crack with solid FM applied: (a) wheel and (b) rail.

\section{Discussion}

\subsection{Effect of solid FM on friction}

It is clear that the FM caused the friction coefficient to decrease (Figs. 4 and 5). The decrease rates were approximately $61 \%, 50 \%, 37 \%, 35 \%, 37 \%$, and $46 \%$ for the slip ratios of $0.17 \%, 0.91 \%, 2.38 \%, 3.83 \%, 4.55 \%$, and $9.43 \%$, respectively. The reduction in the friction coefficient was due to the lubrication properties of PTFE and $\mathrm{MoS}_{2}$, which were the main compositions of the solid FM. After the solid FM was separated from the wheel roller, the friction coefficient did not return to a high level immediately. It remained relatively low and then gradually increased (Fig. 4). This is because when the FM was separated, the FM material remained on the wheel-rail surfaces or trapped in the micro-concaves as shown in Fig. 14(b). The residual material decreases the friction for a period of time (the retention time). This means that solid FM can be applied periodically. With an increase in the slip ratio, the friction force (Fig. 5) increased and the 

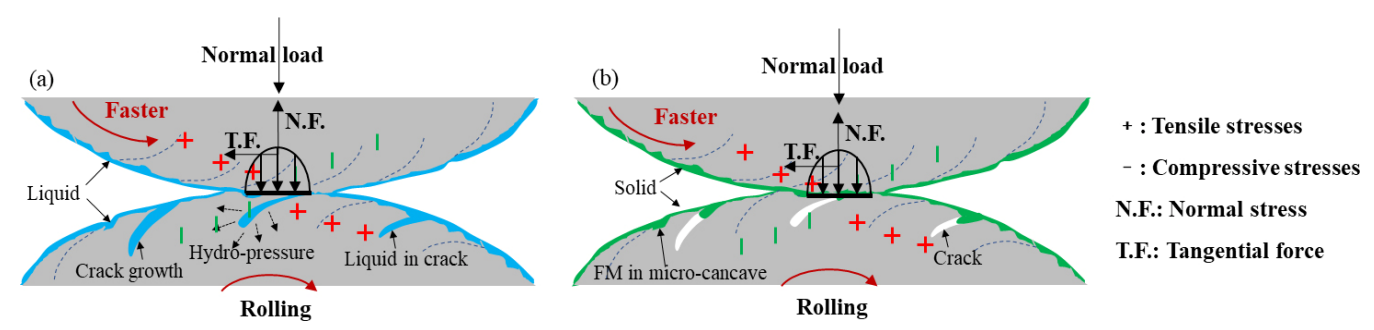

Fig. 14 Effect of FM on RCF cracks: (a) liquid and (b) solid.

wear of the wheel-rail surfaces increased as well [26]; therefore, the residual FM was removed more rapidly as the slip ratio increased and the retention time decreased accordingly (Fig. 6).

\subsection{Effect of solid FM on RCF damage}

The RCF of the wheel-rail materials is mainly caused by cyclic loading on the wheel-rail interface. Under the condition of cyclic contact loading, each cycle of the rolling contact load causes plastic deformation and material hardening. The plastic flow and strain hardening of wheel materials can accumulate up to failure, which can lead to the generation of fatigue cracks and even RCF failures [33]. Thus, thin flakes of material were detached, causing wear of wheel-rail materials [34-36]. With the increase in cumulative plastic deformation, tiny fatigue cracks may initiate on the roller surface if the stress in the contact zone exceeds the elastic shakedown limit of the wheel-rail materials. In addition, the maximum shear force occurs on the contact surface of the wheel-rail under dry conditions. FMs can be applied to the top of the rail to achieve an intermediate friction coefficient in the third body layer. This reduces the traction forces without compromising the braking or friction.

In the current study, compared with the wheel-rail interface without FM, the tangential force (i.e., the friction coefficient multiplied by the constant normal force) with the solid FM decreased by approximately $50 \%$ (under a slip ratio of $0.91 \%$, Fig. 5). Thus, the plastic deformation (Fig. 10) and hardening (Fig. 9) were milder. The average length of the RCF cracks decreased (Figs. 12 and 13), and the wear rates of the wheel-rail materials decreased (Fig. 7). Thus, the application of the solid FM decreases the friction coefficient and alleviates the wear and RCF damage of the wheel-rail materials.

Both liquid and solid FMs are used on trains. In our previous studies, we found that the liquid FMs (or liquid lubricants) could decrease the friction coefficient, but they might lead to severe RCF damage to the wheel-rail surfaces if improperly applied [37]. This is because the liquid can easily flow into the cracks, as shown in Fig. 14(a). When one surface moved against the crack opening direction in the other surface, the crack mouth was first closed, and then the trapped liquid caused a high hydro-pressure under the normal force that accelerated the growth of RCF cracks. For the solid FM as shown in Fig. 14(b), the FM does not easily flow into the cracks; thus, severe RCF damage can be avoided during the rolling-sliding condition. Therefore, solid FMs should have more suitable applications in the field because of the reduction in both friction and RCF damage.

From the results, it can be seen that using the new FM can effectively decrease the wear and RCF of wheel-rail surfaces. Simultaneously, the FM is also a third-body medium (like other foreign objects, such as sand, leaves, and contaminants). Our study can be used to support the wheel-rail contact model considering friction and RCF under a third-body medium. This would be helpful to further understand the phenomenon of wheel-rail friction coefficient in the presence of a third medium.

\section{Conclusions}

1) The friction coefficient was dependent on the slip ratio and solid FM. With an increase in the slip ratio, the friction coefficient increased sharply when the slip ratio was below $1 \%$ and then remained stable. When solid FM was applied, the friction coefficient decreased. After the solid FM was separated from the wheel-rail interface, the friction coefficient increased gradually, and the retention time decreased with the slip ratio. 
2) With the application of the solid FM, the wear rates of the wheel-rail were decreased to $50 \%$ and $65 \%$, respectively, of those without FM at a slip ratio of $0.91 \%$. The thicknesses of the plastic deformation layers of the wheel-rail were reduced from $80-100 \mu \mathrm{m}$ to $60-70 \mu \mathrm{m}$. The surface hardness of the wheel-rail decreased from $600-700 \mathrm{HV}_{0.05}$ to approximately $550 \mathrm{HV}_{0.05}$.

3) The worn surfaces of the wheel-rail were dominated by pits and RCF cracks. With the application of the solid FM, the average lengths of cracks were reduced from $84-120 \mu \mathrm{m}$ to $17-97 \mu \mathrm{m}$. Meanwhile, subsurface cracks were generated in the absence of the FM, but no subsurface cracks were observed with the application of the solid FM.

\section{Acknowledgements}

This study was supported by the National Key R\&D Program Intergovernmental Key Items for International Scientific and Technological Innovation Cooperation (No. 2018YFE0109400), Sichuan Science and Technology Program (No. 2020YFH0057), and Fundamental Research Funds for the Central Universities (No. 2682020CX29). The study was also carried out under the Project 8JCH1042 with financial support from the Ministry of Education, Youth and Sports of the Czech Republic.

Open Access This article is licensed under a Creative Commons Attribution 4.0 International License, which permits use, sharing, adaptation, distribution and reproduction in any medium or format, as long as you give appropriate credit to the original author(s) and the source, provide a link to the Creative Commons licence, and indicate if changes were made.

The images or other third party material in this article are included in the article's Creative Commons licence, unless indicated otherwise in a credit line to the material. If material is not included in the article's Creative Commons licence and your intended use is not permitted by statutory regulation or exceeds the permitted use, you will need to obtain permission directly from the copyright holder.

To view a copy of this licence, visit http://creativecommons.org/licenses/by/4.0/.

\section{References}

[1] Buckley-Johnstone L E, Trummer G, Voltr P, Six K, Lewis R. Full-scale testing of low adhesion effects with small amounts of water in the wheel/rail interface. Tribol Int 141: 105907 (2020).

[2] Galas R, Omasta M, Shi L, Ding H, Wang W, Krupka I, Hartl M. The low adhesion problem: The effect of environmental conditions on adhesion in rolling-sliding contact. Tribol Int 151: 106521 (2020).

[3] Zeng D, Xu T, Wang J, Lu L, Meng W, Jiang B, Zou Q. Investigation of the crack initiation of subsurface rolling contact fatigue in railway wheels. Int J Fatigue 130: 105281 (2020).

[4] Shahani A R, Babaei M. The crack propagation path for a system of surface and subsurface cracks and their interactions due to rolling contact fatigue. Acta Mech 231(5): 1751-1764 (2020).

[5] Meacci M, Shi Z Y, Butini E, Marini L, Meli E, Rindi A. A local degraded adhesion model for creep forces evaluation: An approximate approach to the tangential contact problem. Wear 440-441: 203084 (2019).

[6] Butini E, Marini L, Meacci M, Meli E, Rindi A, Zhao X J, Wang W J. An innovative model for the prediction of wheelRail wear and rolling contact fatigue. Wear 436-437: 203025 (2019)

[7] Olofsson U. A multi-layer model of low adhesion between railway wheel and rail. Proc Inst Mech Eng F: J Rail Rapid Transit 221(3): 385-389 (2007)

[8] Seo J W, Jun H K, Kwon S J, Lee D H. Effect of friction modifier on rolling contact fatigue and wear of wheel and rail materials. Tribol Trans 61(1): 19-30 (2018)

[9] Stock R, Stanlake L, Hardwick C, Yu M, Eadie D, Lewis R. Material concepts for top of rail friction managementclassification, characterisation and application. Wear 366-367: 225-232 (2016)

[10] Eadie D T, Santoro M, Powell W. Local control of noise and vibration with KELTRACK ${ }^{\mathrm{TM}}$ friction modifier and Protector ${ }^{\circledR}$ trackside application: An integrated solution. J Sound Vib 267(3): 761-772 (2003)

[11] Eadie D T, Kalousek J, Chiddick K C. The role of high positive friction (HPF) modifier in the control of short pitch corrugations and related phenomena. Wear 253(1-2): 185-192 (2002)

[12] Suda Y, Iwasa T, Komine H, Tomeoka M, Nakazawa H, Matsumoto K, Nakai T, Tanimoto M, Kishimoto Y. Development of onboard friction control. Wear 258(7-8): 1109-1114 (2005) 
[13] Eadie D T, Elvidge D, Oldknow K, Stock R, Pointner P, Kalousek J, Klauser P. The effects of top of rail friction modifier on wear and rolling contact fatigue: Full-scale railwheel test rig evaluation, analysis and modelling. Wear 265(9-10): 1222-1230 (2008)

[14] Lewis R, Gallardo E A, Cotter J, Eadie D T. The effect of friction modifiers on wheel/rail isolation. Wear 271(1-2): 71-77 (2011)

[15] Hardwick C, Lewis S, Lewis R. The effect of friction modifiers on wheel/rail isolation at low axle loads. Proc Inst Mech Eng F: J Rail Rapid Transit 228(7): 768-783 (2014)

[16] Lewis R, Dwyer-Joyce R S, Lewis J. Disc machine study of contact isolation during railway track sanding. Proc Inst Mech Eng F: J Rail Rapid Transit 217(1): 11-24 (2003)

[17] Abbasi S, Olofsson U, Zhu Y, Sellgren U. Pin-on-disc study of the effects of railway friction modifiers on airborne wear particles from wheel-rail contacts. Tribol Int 60: 136-139 (2013)

[18] Wang W J, Liu T F, Wang H Y, Liu Q Y, Zhu M H, Jin X S. Influence of friction modifiers on improving adhesion and surface damage of wheel/rail under low adhesion conditions. Tribol Int 75: 16-23 (2014)

[19] Arias-Cuevas O, Li Z, Lewis R, Gallardo-Hernández E A. Rolling-sliding laboratory tests of friction modifiers in dry and wet wheel-rail contacts. Wear 268(3-4): 543-551 (2010)

[20] Hu Y, Guo L C, Maiorino M, Liu J P, Ding H H, Lewis R, Meli E, Rindi A, Liu Q Y, Wang W J. Comparison of wear and rolling contact fatigue behaviours of bainitic and pearlitic rails under various rolling-sliding conditions. Wear 460-461(4): 203455 (2020)

[21] Hu Y, Zhou L, Ding H H, Tan G X, Lewis R, Liu Q Y, Guo $\mathrm{J}$, Wang W J. Investigation on wear and rolling contact fatigue of wheel-rail materials under various wheel/rail hardness ratio and creepage conditions. Tribol Int 143: 106091 (2020)

[22] Khalladi A, Elleuch K. Effect of surface topography with different groove angles on tribological behavior of the wheel/rail contact using alternative machine. Friction 4(3): 238-248 (2016)

[23] Deters L, Proksch M. Friction and wear testing of rail and wheel material. Wear 258(7-8): 981-991 (2005)

[24] Wang W J, Guo J, Liu Q Y, Zhu M H, Zhou Z R. Study on relationship between oblique fatigue crack and rail wear in curve track and prevention. Wear 267(1-4): 540-544 (2009)

[25] Donzella G, Faccoli M, Ghidini A, Mazzù A, Roberti R.
The competitive role of wear and RCF in a rail steel. Eng Fract Mech 72(2): 287-308 (2005)

[26] Guo L C, Zhu W T, He C G, Ma L, Wang W, Liu Q. Analysis on wear and damage characteristics of $\mathrm{U}_{75} \mathrm{~V}$ rail under different slip ratio conditions. J Mech Eng 54(4): 167-175 (2018)

[27] Sandström J. Subsurface rolling contact fatigue damage of railway wheels-a probabilistic analysis. Int $J$ Fatigue 37: 146-152 (2012)

[28] Sajjadi S H, Salimi-Majd D, Ostad Ahmad Ghorabi M J. Development of a brittle fracture criterion for prediction of crack propagation path under general mixed mode loading. Eng Fract Mech 155: 36-48 (2016)

[29] Spiryagin M, Sajjad M, Nielsen D, Sun Y Q, Raman D, Chattopadhyay G. Research methodology for evaluation of top-of-rail friction management in Australian heavy haul networks. Proc Inst Mech Eng F: J Rail Rapid Transit 228(6): 631-641 (2014)

[30] Lu X, Makowsky T W, Eadie D T, Oldknow K, Xue J L, Jia J Z, Li G B, Meng X H, Xu Y D, Zhou Y. Friction management on a Chinese heavy haul coal line. Proc Inst Mech Eng F: J Rail Rapid Transit 226(6): 630-640 (2012)

[31] Hardwick C, Lewis R. The effects of alternative top of rail friction materials on pre-existing rolling contact fatigue cracks. In Proceedings of the Second International Conference on Railway Technology: Research, Development and Maintenance, Civil-Comp Press, Stirlingshire, UK, Paper $181,2014$.

[32] Wang W J, Hu J, Guo J, Liu Q Y, Zhu M H. Effect of laser cladding on wear and damage behaviors of heavy-haul wheel/rail materials. Wear 311(1-2): 130-136 (2014)

[33] Kapoor A. Wear by plastic ratchetting. Wear 212(1): 119-130 (1997)

[34] Suh N P. The delamination theory of wear. Wear 25(1): 111-124 (1973)

[35] Hu Y, Zhou L, Ding H H, Lewis R, Liu Q Y, Guo J, Wang W J. Microstructure evolution of railway pearlitic wheel steels under rolling-sliding contact loading. Tribol Int 154: 106685 (2021)

[36] Wang Y, Ding H, Zou Q, Xiao F, Zhang X, Wang W, Guo J, Liu Q. Research progress on rolling contact fatigue of railway wheel treads. Surf Tech 49(5): 120-128 (2020).

[37] Wang W J, Lewis R, Evans M D, Liu Q Y. Influence of different application of lubricants on wear and pre-existing rolling contact fatigue cracks of rail materials. Tribol Lett 65(2): 1-15 (2017) 


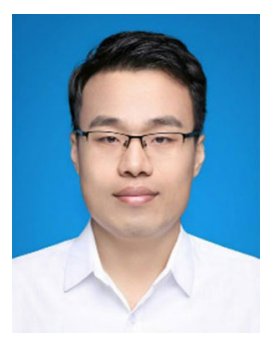

Jingdong SONG. He received his B.S. degree in transportation from Ludong University, China, in 2013. He received his M.S. degree in vehicle engineering from Southwest

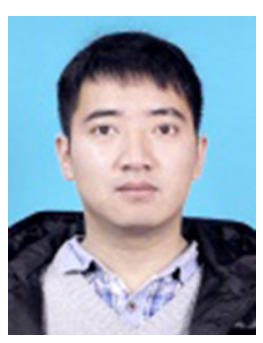

Lubing SHI. He received his B.S. degree in industrial engineering in 2013 from Xi'an Polytechnic University, China. He is studying at

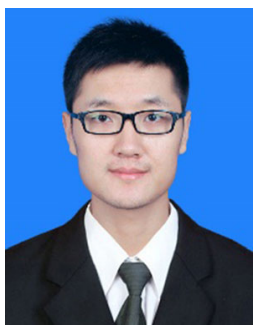

Haohao DING. He received his $\mathrm{Ph} . \mathrm{D}$. degree in materials science from Ecole Centrale de Lyon, France, in 2018. Then he joined the Tribology Research Institute, State

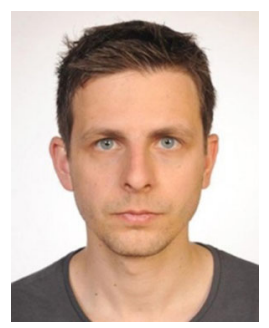

Radovan GALAS. He received his B.S., M.S., and Ph.D. degrees in mechanical engineering from Brno University of Technology, Czech Republic, in 2011, 2013, and 2018, respectively. His current position

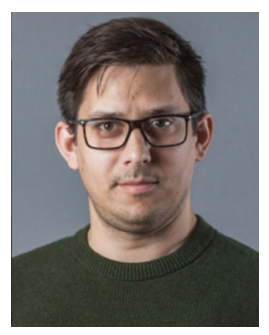

Milan OMASTA. He received his B.S., M.S., and Ph.D. degrees in mechanical engineering from Brno University of Technology, Czech Republic, in 2007, 2009, and 2013, respectively. His current position
Jiaotong University, China, in 2019. He is studying at the Institute of Aeronautics Engine, School of Mechanical Engineering, Xi'an Jiaotong University as a Ph.D. student. He is now focusing on the wheel-rail tribology and surface engineering.

the Tribology Research Institute, State Key Laboratory of Traction Power, Southwest Jiaotong University, as a Ph.D. student. He is now focusing on the adhesion of wheel and rail.

Key Laboratory of Traction Power, Southwest Jiaotong University, China. His current position is an assistant professor. His research interests include the wheel-rail tribology, laser surface treatment, coating, etc.

is an assistant professor and a member of Railway Research Group at Institute of Machine and Industrial Design, Faculty of Mechanical Engineering, Brno University of Technology. His research focuses on wheel-rail tribology, especially on friction management methods.

is an assistant professor and the head of Railway Research Group at Institute of Machine and Industrial Design, Faculty of Mechanical Engineering, Brno University of Technology. His research areas cover friction and lubrication between wheel and rail and elastohydrodynamic lubrication. 


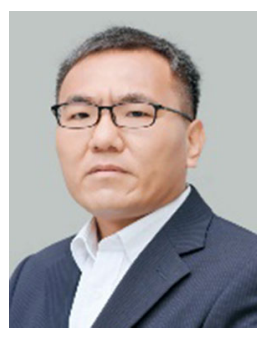

Wenjian WANG. He received his Ph.D. degree in mechanical design and theory from Southwest Jiaotong University, China, in 2008. Then he continued to work at the Tribology Research Institute, State

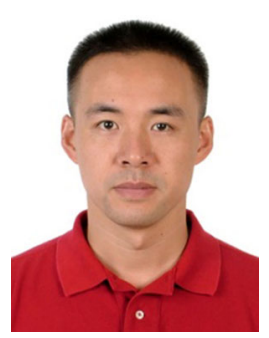

Jun GUO. He received his Ph.D. degree in mechanical design and theory from Southwest Jiaotong University, China, in 2007. Then he

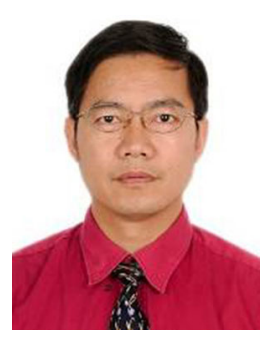

Qiyue LIU. He received his Ph.D. degree in mechanical design and theory from Southwest Jiaotong University, China, in 1999. Then he continued to work at the Tribology

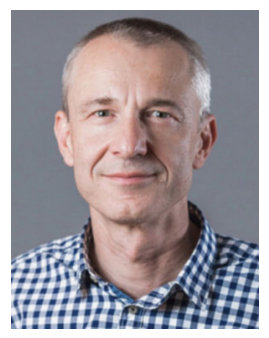

Martin HARTL. He received his M.S. and Ph.D. degrees in mechanical engineering from Brno University of Technology, Czech Republic, in 1990 and 1997, respectively. His current position is a professor and the head
Key Laboratory of Traction Power, Southwest Jiaotong University. His current position is a researcher. His research interests include the wheel-rail friction control technology, wheel-rail wear and damage evaluation technology, laser surface treatment, etc.

continued to work at Southwest Jiaotong University. His current position is a researcher. His research interests include the rail grinding technology, wheelrail wear, rolling contact fatigue, etc.

Research Institute, State Key Laboratory of Traction Power, Southwest Jiaotong University. His current position is a professor. His research interests include the tribology, wheel-rail service and reliability, mechanical engineering, etc.

of Institute of Machine and Industrial Design, Faculty of Mechanical Engineering, Brno University of Technology. His research areas cover the boundary, mixed and elastohydrodynamic lubrication, roughness effect, and biotribology. 